\title{
Bilateral asymmetry in bleaching susceptibility within a giant clam, Tridacna maxima
}
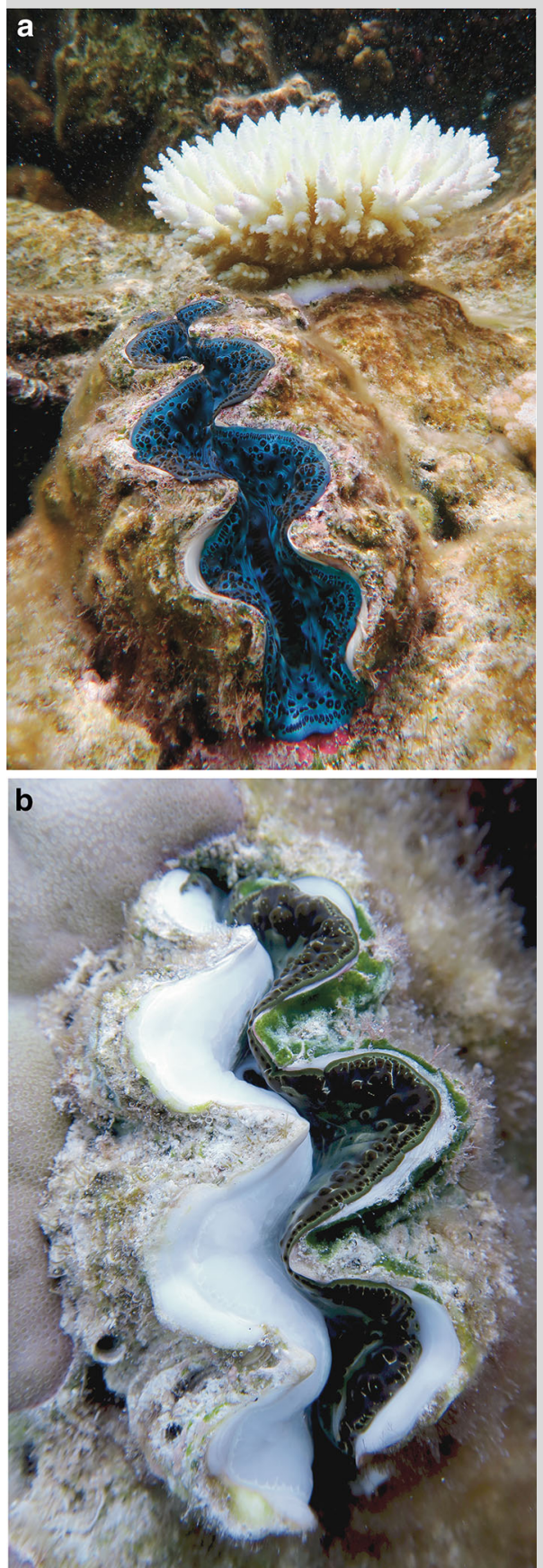

Fig. 1 Bleaching event observed during the El Niño 2014-2016 event in Tetiaroa atoll. a Resistant giant clams Tridacna maxima compared to one sensitive Acropora coral colonies A. tenuis, and $\mathbf{b}$ bilateral asymmetry in bleaching susceptibility of a giant clam Tridacna maxima
Giant clams, like zooxanthellate corals, are reliant on Symbiodinium. The intercellular Symbiodinium into the giant clams can provide up to $100 \%$ of the host's energetic requirements through the photosynthetic activity (uptake and fixation of inorganic compounds) (Fisher et al. 1985). However, such associations are vulnerable to stressinduced expulsion of the algae, often associated with increased sea surface temperatures. While the physiological stress of bleaching is largely reported and studied in corals, it is rare and thus still poorly understood in giant clams.

In April 2016, the sea surface temperature within the lagoon of Tetiaroa Atoll, French Polynesia $\left(17^{\circ} 0^{\prime} \mathrm{S}, 149^{\circ} 33^{\prime} \mathrm{W}\right)$, reached $31-32^{\circ} \mathrm{C}$. These temperatures are $2-3{ }^{\circ} \mathrm{C}$ higher than the bleaching thermal threshold historically determined for the Society archipelago (e.g. $29.2^{\circ} \mathrm{C}$ for Moorea, Adjeroud et al. 2009). This positive thermal anomaly caused coral bleaching mainly of Acropora and partly other coral species. Conversely, despite the high density of giant clams Tridacna maxima in the lagoon, most of them did not display any bleaching signs (Fig. 1a). However, we did observe one individual with bilateral asymmetry in bleaching susceptibility (Fig. 1b). This suggests that the two sides of the organisms are differentially resistant and/or adapted to thermal stress. One possible explanation that could account for bilateral thermal tolerance is the occurrence of distinct Symbiodinium communities between both sides of giant clams, as certain clades of Symbiodinium are more resistant to seawater warming than others. Indeed, giant clams are known to be associated with different clades (A, C and/or D) of Symbiodinium (DeBoer et al. 2012), but whether Symbiodinium communities vary between the two hemispheres of the same individual remains to be tested.

Understanding differential susceptibility and resistance to thermal bleaching within and among coral reef organisms such as giant clams is critically important given sustained and ongoing ocean warming.

Acknowledgements This work was carried out as part of the 'Tetiaroa Holistic Reef Replenishment' Project with Tetiaroa Society 'Mission blue' in which CRIOBE was the lead scientific Agency. This project was funded by the Leonardo DiCaprio Foundation.

\section{References}

Adjeroud M, Michonneau F, Edmunds PJ, Chancerelle Y, Loma TL, Penin L, Thibaut L, VidalDupiol J, Salvat B, Galzin R (2009) Recurrent disturbances, recovery trajectories, and resilience of coral assemblages on a South Central Pacific reef. Coral Reefs 28:775-780. https://doi.org/10.1007/s00338-009-0515-7

DeBoer TS, Baker AC, Erdmann MV, Ambariyanto JPR, Barber PH (2012) Patterns of Symbiodinium distribution in three giant clam species across the biodiverse Bird's Head region of Indonesia. Mar Ecol Prog Ser 444:117-132. https://doi.org/10.3354/meps09413

Fisher CR, Fitt WK, Trench RK (1985) Photosynthesis and respiration in Tridacna gigas as a function of irradiance and size. Biol Bull 169:230-245

H. Rouzé (D) $(\bowtie) \cdot$ L. Hédouin

PSL Research University, EPHE-UPVD-CNRS, USR 3278 CRIOBE, BP 1013, 98729

Papetoai, Moorea, French Polynesia

e-mail: heloise.rouze@gmail.com

H. Rouzé (D) - L. Hédouin

Laboratoire d'Excellence « CORAIL », Papetoai, French Polynesia 